\title{
GRUPOS DE ÁCAROS (ARTHROPODA, ACARI) ENCONTRADOS EM ARECACEAE DA MATA ATLÂNTICA DO ESTADO DE SÃO PAULO
}

\author{
Geraldo Pereira de Arruda Filho \\ Gilberto José de Moraes
}

Biota Neotropica v2 (n1) - http://www.biotaneotropica.org.br/v2n1/pt/abstract?article+BN01502012002

Recebido em 01 de março de 2002

Revisado em 20 de junho de 2002

Publicado em 30 de junho de 2002

\begin{abstract}
Geraldo Pereira de Arruda Filho \& Gilberto José de Moraes;
Departamento de Entomologia, Fitopatologia e Zoologia Agrícola, ESALQ -USP

Caixa postal 9, 13418 900, Piracicaba SP www.ciagri.usp.br.

Autor para correspondência: Gilberto José de Moraes (gjmoraes@ carpa.ciagri.usp.br).
\end{abstract}

\begin{abstract}
Mites groups (arthropoda, acari) found on arecaceae in the Atlantic Forest of the state of São Paulo.

This work reports 96 mite species belonging to 54 genera in 22 families and 4 suborders (Prostigmata, Mesostigmata, Metastigmata and Astigmata) found on inflorescences, fruits, terminal shoots and foliage of native Arecaceae plants in the Atlantic Forest of the State of São Paulo, in Cananéia, Pariquera-Açu, Piracicaba and São Pedro. Samplings were conducted in January and February (summer) April and May (fall), July and August (winter) and October and November (spring). Mites were more numerous in the fall. The majority of the mites were found in the inflorescences (50,2\% of the mites collected). Mesostigmata was the most abundant suborder, representing 62,4\% of the mites collected (Eriophyoidea and Oribatida were not considered in this study). Prostigmata was the most diverse suborder (13 families). Ameroseiidae was the most numerous family $(49,2 \%$ of the mites collected); more than $99 \%$ of the mites of this family were found in the inflorescences of Geonoma brevispatha Barb. Rodr. e Geonoma schottiana Mart.. Phytoseiidae was the second most numerous family (11,2\% of the mites collected); it was the most abundant family on the folioles.
\end{abstract}

Key Words: mites, suborder, family

\section{Resumo}

Grupos de ácaros (arthropoda, acari) encontrados em arecaceae da Mata Atlântica do estado de São Paulo.

Este trabalho relata 96 espécies de ácaros pertencentes a 54 gêneros de 22 famílias e 4 subordens (Prostigmata, Mesostigmata, Astigmata e Metastigmata) encontradas em inflorescências, frutos, brotos terminais e folíolos de 9 espécies nativas de Arecaceae da Mata Atlântica do Estado de São Paulo, nos municípios de Cananéia, Pariquera-Açu, Piracicaba e São Pedro. As coletas foram realizadas nos meses de janeiro e fevereiro (verão, meio e final da estação chuvosa), abril e maio (outono, início da estação seca), julho e agosto (inverno, meio e final da estação seca) e outubro e novembro (primavera, início da estação chuvosa). Maior quantidade de ácaros foi encontrada em abril e maio. A maioria dos ácaros foi coletada nas inflorescências (50,2\% dos indivíduos coletados). Mesostigmata foi a mais abundante, representando $62,4 \%$ dos ácaros coletados (Eriophyoidea e Oribatida não foram considerados neste estudo). Prostigmata foi a subordem mais diversa (13 famílias). Ameroseiidae foi a família mais numerosa (49,2\% dos ácaros coletados); mais de $99 \%$ dos representantes desta família foram encontrados em inflorescências de Geonoma brevispatha Barb. Rodr. e Geonoma schottiana Mart.. Phytoseiidae foi a segunda família mais numerosa (11,2\% dos ácaros coletados), sendo a mais abundante em folíolos.

Palavras-chave: ácaros, subordem, família. 


\section{INTRODUÇÃO}

Em sua maioria, as Arecaceae são de grande importância econômica pelos diferentes produtos que podem oferecer. Do coqueiro, os frutos são extensamente comercializados para o consumo de "água de coco", a polpa pode ser utilizada para consumo direto ou produção de óleo comestível e as fibras são utilizadas na indústria automotiva. O tucum (Bactris e Astrocarium) fornece material para tecelagem (Joly 1991). As folhas são utilizadas na construção de habitações ou na extração de cera. A juçara (Euterpe edulis Mart.), o açai (Euterpe oleracea Mart.) e a pupunha (Bactris gasipaes Kunth) são utilizadas para obtenção de palmito. A juçara (E. edulis ) é uma espécie de ampla distribuição ao longo do litoral brasileiro, ocorrendo naturalmente desde o sul da Bahia até o Rio Grande do Sul (Lorenzi 1996). É uma planta com diversas aplicações em construções rurais, podendo ainda ser utilizada na produção de papel e celulose. O açai é uma palmeira rústica originária da Amazônia (Lorenzi 1993). O uso desta planta é bastante extenso, sendo a raiz empregada como vermífugo, o estipe nas construções rurais e os frutos na alimentação (Jardim \& Anderson 1987). A pupunha também é originária da Amazônia e tem sido extensivamente cultivada nos dias atuais em algumas regiões do Brasil. O babaçu (Orbignya martiana Barb.Rodr.) é utilizado na produção de palmito e óleo lubrificante; suas fibras são utilizadas na confecção de chapéu (Gonsalves 1955). Muitas arecáceas são utilizadas em projetos paisagísticos, na criação de ambientes de aspecto tropical (Lorenzi 1996).

A diversidade de espécies de ácaros que ocorrem em arecáceas no Brasil ainda é pouco conhecida. Em um extenso trabalho para se conhecer os ácaros de arecáceas da Mata Atlântica. Gondim Jr. (2000) encontrou cerca de 62 espécies de ácaros pertencentes a 12 famílias em folíolos dessas plantas.

Dentre os ácaros fitófagos encontrados neste grupo de plantas no Brasil, os mais diversos tem sido os representantes da superfamília Eriophyoidea (Flechtmann 1994, 1998, Flechtmann \& Santana 1997, Santana \& Flechtmann 1998; Santana et al 1994). Até o momento, 11 espécies de eriofídeos foram identificadas em arecáceas (Gondim Jr. et al. 2000). O ácaro Aceria guerreronis Keifer, causador da necrose e queda de frutos em coqueiro (Cocus nucifera L.) foi o primeiro eriofídeo relatado em palmeiras no Brasil (Robbs \& Peracchi 1965). O ácaro é responsável pela depreciação dos frutos do coqueiro, e em casos de ataques severos, até pela queda de frutos. Atualmente, o ácaro encontra-se disseminado em todas as regiões tropicais do mundo, constituindo-se uma das mais importantes pragas do coqueiro (Moore \& Howard 1996).

Ácaros fitófagos das famílias Tetranychidae e Tenuipalpidae (Ferreira 1997, Santana \& Flechtmann 1998) e ácaros predadores das famílias Phytoseiidae, Bdellidae, Cunaxidae, Raphignathidae, Ascidae, Cheyletidae e Stigmaeidae (Santana \& Flechtmann 1998, Gondim Jr. \& Moraes 2001) também têm sido relatados em arecáceas no Brasil. O maior número de ácaros predadores encontrados nestas plantas pertence à família Phytoseiidae, tendo sido identificadas até o momento 44 espécies desta família (Flechtmann 1967, Santana \& Flechtmann 1998, Gondim Jr. \& Moraes 2001).

Este trabalho foi realizado com o intuito de aprimorar os conhecimentos sobre a acarofauna em arecáceas nativas da Mata Atlântica do Estado de São Paulo.

\section{MATERIAL E MÉTODOS}

Foram realizadas 4 coletas de amostras na Mata Atlântica, uma em cada estação do ano, no período de janeiro a novembro de 2000.

As coletas foram realizadas nos municípios de Cananéia, Pariquera-Açu, Piracicaba e São Pedro (Tabela 1), divididos em três regiões. O período dedicado para as coletas foi de aproximadamente 3 dias em cada região, sendo estas realizadas em 3 plantas de 5 espécies distintas de arecáceas nativas, em cada região de coleta, em um total de 9 espécies de palmeiras, a saber: Cananéia: Astrocarium aculeatissimum (Schott), Bactris setosa Mart., Euterpe edulis Mart, Geonoma schottiana Mart e Syagrus romanzoffiana (Cham.); Pariquera-Açu: Astrocarium aculeatissimum (Schott), Attalea dubia (Mart.), Bactris setosa Mart., Euterpe edulis Mart e Syagrus romanzoffiana (Cham.); Piracicaba: Acrocomia aculeata (Jacq.) Lodd, Euterpe edulis Mart e Syagrus romanzoffiana (Cham.); São Pedro: Geonoma brevispatha Barb. Rodr. e Syagrus oleracea (Mart.) Becc.

\begin{tabular}{|c|c|c|c|c|}
\hline \multicolumn{4}{|c|}{ AÇU } & SÃO PEDRO \\
\hline & Área particular & Núcleo de & Estação & Área particular- \\
\hline \multirow[t]{4}{*}{ Localização } & - SP226, & Agronomia do & Ecológica de & SP304, Rodovia \\
\hline & Rodovia J.H. & Vale do & Ibicatu & Geraldo de \\
\hline & de Oliveira & Ribeira-IAC & & Barros, km 204 \\
\hline & Rosa, km 16 & & & \\
\hline \multirow[t]{2}{*}{ Coordenadas } & $24^{\circ} 53^{\prime} 45^{\prime \prime S ~ e ~}$ & $24^{\circ} 36^{\prime} 41^{\prime \prime S ~ e ~}$ & $22^{\circ} 46^{\prime} 43^{\prime \prime S ~ e ~}$ & $22^{\circ} 33^{\prime} 57^{\prime \prime} \mathrm{S} \mathrm{e}$ \\
\hline & $47^{\circ} 50^{\prime} 17^{\prime \prime} \mathrm{W}$ & $47^{\circ} 53^{\prime} 23^{\prime \prime} \mathrm{W}$ & $47^{\circ} 49^{\prime} 32^{\prime \prime} \mathrm{W}$ & $47^{\circ} 57^{\prime} 28^{\prime \prime} \mathrm{W}$ \\
\hline \multirow[t]{3}{*}{ Tipo de vegetação } & Restinga & Floresta & Floresta & Floresta \\
\hline & arbórea & umbrófila & estacional & estacional \\
\hline & & densa & semidecídua & decídua \\
\hline
\end{tabular}

Tabela 1. Locais das coletas realizadas no ano 2000, coordenadas e respectivos tipos de vegetação

A amostra de cada planta constou da brotação terminal (apenas as folhas em desenvolvimento foram tomadas, sem retirar o meristema apical) e 20 folíolos tomados de folhas da região mediana da copa de cada planta. Os folíolos foram retirados de uma única folha, sendo 5 do terço apical, 10 do terço mediano e 5 do terço basal. Sempre que presentes, 20 ráquilas (ramificações do eixo principal da inflorescência) e 20 frutos por planta também foram amostrados. Estes foram tomados ao acaso. 
Todos os folíolos de cada folha foram acondicionados em saco de papel, que por sua vez foi colocado em um saco plástico, que foi acondicionado em uma caixa de isopor refrigerada $\left(12-21^{\circ} \mathrm{C}\right)$ para evitar perda de ácaros durante o transporte. Flores, frutos ou broto terminal de cada planta foram colocados separadamente em recipientes de plástico de 5 litros, sendo $30 \%$ deste volume ocupado com álcool etílico a $70 \%$; logo em seguida, os recipientes foram agitados para imobilizar os ácaros e fazê-los cair na solução.

O material coletado foi levado ao laboratório de Acarologia do Setor de Zoologia do Departamento de Entomologia, Fitopatologia e Zoologia Agrícola da Escola Superior de Agricultura "Luiz de Queiroz" Universidade de São Paulo, sendo os recipientes com as inflorescências, os frutos ou os brotos terminais mantidos à temperatura ambiente e os folíolos armazenados em refrigerador (aproximadamente $10^{\circ} \mathrm{C}$ ), por um período máximo de 10 dias, até a coleta dos ácaros.

Os folíolos foram examinados sob microscópio estereoscópio, coletando-se os ácaros em álcool etílico a $70 \%$ para posterior preparação de lâminas. Os ácaros foram coletados separadamente, de acordo com a face do folíolo em que se encontravam. Diferentemente dos outros ácaros, os Eriophyoidea foram conservados em AGA (ácool etílico $240,0 \mathrm{cc}$, ácido acético glacial 30,0cc, glicerina 30,0cc, sorbitol 23,8g), até serem montados para identificação (Amrine \& Manson 1996). Para comparação das densidades de ácaros em cada espécie vegetal, os números de ácaros encontrados em cada época de coleta e em cada espécie vegetal foram divididos pela área estimada dos folíolos amostrados. Em cada caso, a área considerada correspondeu à somatória de ambas as faces dos folíolos.

Os frutos coletados foram separados das brácteas, recolocados nos recipientes onde estavam armazenados $\mathrm{e}$ agitados novamente para que os ácaros caíssem na solução. Posteriormente, o material mais grosseiro foi retirado manualmente e o restante da solução foi passado por uma peneira de 400 aberturas por polegada quadrada (ABNT 400). O resíduo retido na peneira foi transferido para siracusa e levado ao microscópio estereoscópio para separação dos ácaros. Estes foram acondicionados em álcool etílico a 70\%, onde permaneceram até a montagem. As inflorescências e os brotos terminais foram processados de forma semelhante.

Os ácaros de corpo delicado foram montados entre lâmina e lamínula de microscópio em meio de Hoyer (Flechtmann 1975), sem qualquer tratamento prévio. Ácaros muito esclerotizados ou escuros foram previamente tratados com lactofenol (Flechtmann 1975) e lavados com água destilada antes da montagem em meio de Hoyer. A identificação de muitas espécies de Tetranychidae comumente exige a montagem de machos na posição lateral para a observação do edéago, e por isso estes foram assim montados. Os demais ácaros foram montados na posição dorso-ventral. No caso dos ácaros da família Ameroseiidae, encontrados em grande quantidade (mais de 1000 ácaros) em inflorescências de G. schottiana e $G$. brevispatha, apenas uma amostra destes organismos foi montada, conservando-se o restante em álcool etílico a $70 \%$ para eventuais estudos futuros. Concluída a preparação, as lâminas foram colocadas em estufa a 45 $50^{\circ} \mathrm{C}$ por uma semana, sendo em seguida efetuada a lutagem com resina aquídica (Verniz Cristal ). Ao final, estas foram etiquetadas.

Os ácaros foram separados por famílias através de observações feitas ao microscópio, usando uma chave para separação dos principais grupos de ácaros plantícolas, elaborada pelo Professor G. J. de Moraes para uso na disciplina Acarologia, oferecida no curso de graduação da ESALQ USP, e as chaves elaboradas por Krantz (1978). Os ácaros foram identificados até gênero principalmente com base nas chaves para diferentes famílias, utilizadas no Curso de Verão de Acarologia da "Ohio State University", Estados Unidos da América do Norte (não publicadas). A identificação foi facilitada pela consulta à tese de doutorado de Gondim Jr. (2000), que fez um estudo dos ácaros da face ventral dos folíolos de arecáceas da Mata Atlântica de Pernambuco e São Paulo.

Todos os ácaros foram coletados por G. P. de Arruda Filho, sendo os espécimes representativos de todas as espécies coletadas depositados na coleção de referência de ácaros do Setor de Zoologia da ESALQ - USP.

\section{RESULTADOS E DISCUSSÃO}

Foi encontrado neste estudo um total de 5.853 ácaros, sem incluir os Eriophyoidea. A maioria dos ácaros (50,2\% dos indivíduos) foi coletada nas inflorescências (Figura 1). Poucos ácaros foram encontrados nos frutos e brotos terminais.

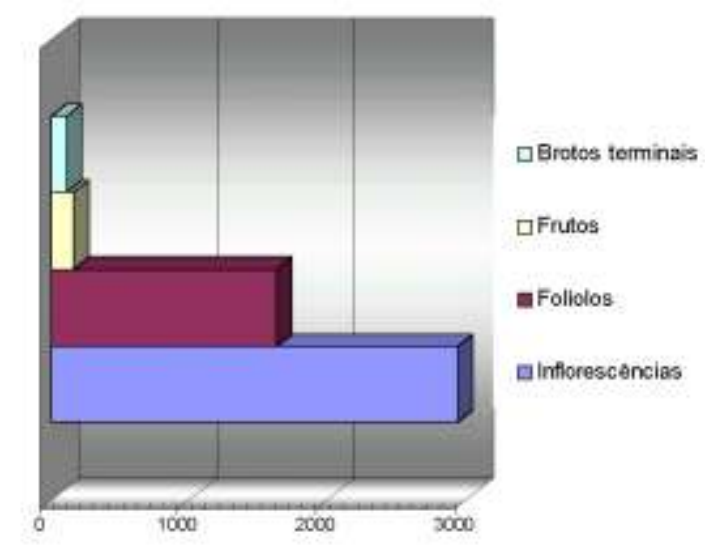

Figura 1 - Totais de ácaros encontrados em inflorescências, foliolos, frutos e brotos terminais de Arecaceae em regiões da Mata Atlântica do Estado de São Paulo, 2000.

Os ácaros encontrados pertencem às subordens Mesostigmata, Metastigmata, Prostigmata, Astigmata e Oribatida. A subordem mais numerosa foi Mesostigmata, representando mais de $62,4 \%$ de todos os ácaros coletados (Figura 2). Os percentuais das demais subordens somados representaram pouco mais que a metade do percentual daquela subordem. 


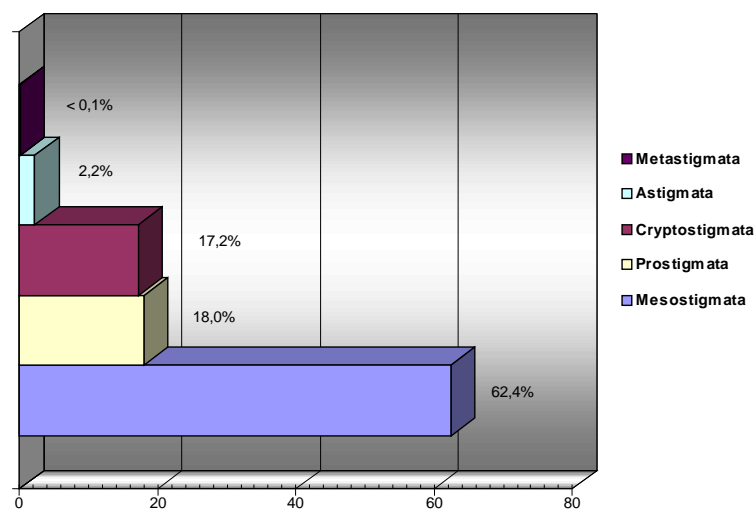

Figura 2 - Proporções dos ácaros em cada subordem encontrados em Arecaceae em regiões da Mata Atlântica do Estado de São Paulo, 2000.

\subsection{Diversidade de ácaros nas subordens} encontradas

A família Ameroseiidae representou 78,7\% dos ácaros da subordem Mesostigmata (Figura 3). As outras duas famílias mais numerosas, Phytoseiidae e Ascidae, representaram 17,9 e 3,1\%, respectivamente, dos ácaros desta subordem. Outras famílias encontradas foram Ologamasidae, Polyaspididae, Uropodidae, Digamasellidae e Laelapidae; a somatória dos ácaros destas famílias correspondeu a cerca de $0,3 \%$ dos Mesostigmata encontrados.Não considerando os Eriophyoidea, os ácaros da subordem Prostigmata, apesar de menos numerosos que aqueles da subordem Mesostigmata, apresentaram maior diversidade de famílias (Figura 3). Três grupos de famílias podem ser distinguidos dentro desta subordem. As famílias Stigmaeidae, Tenuipalpidae, Tydeidae e Tetranychidae correspondem ao grupo das famílias mais abundantes; Cunaxidae, Eupodidae, Tarsonemidae, Cheyletidae e Bdellidae correspondem ao grupo de famílias de abundância intermediária; Anystidae, Camerobiidae, Microtrombidiidae e Raphignathidae correspondem ao grupo de famílias menos abundantes. Somados, os ácaros do primeiro grupo representaram 72,4\% dos ácaros da subordem Prostigmata; os do segundo grupo, $26,8 \%$, e os do terceiro grupo, $0,7 \%$. Tivessem os Eriophyoidea sido quantificados, estariam certamente entre as famílias mais numerosas.

As famílias Acaridae e Winterschmidtiidae representaram 99,2\% dos ácaros da subordem Astigmata encontrados neste estudo (Figura 3). Este resultado está comparável com a literatura, que cita estas como as famílias da subordem Astigmata mais frequientes em folhas de plantas (Walter \& Proctor 1999). Os Winterschmidtiidae, família mais numerosa desta subordem em folíolos das espécies vegetais amostradas, apresentaram diferença significativa (Duncan 5\%) quanto à espécie vegetal em que foram encontrados. Ocorreram em maior quantidade sobre $A$. aculeata e A. Dubia.

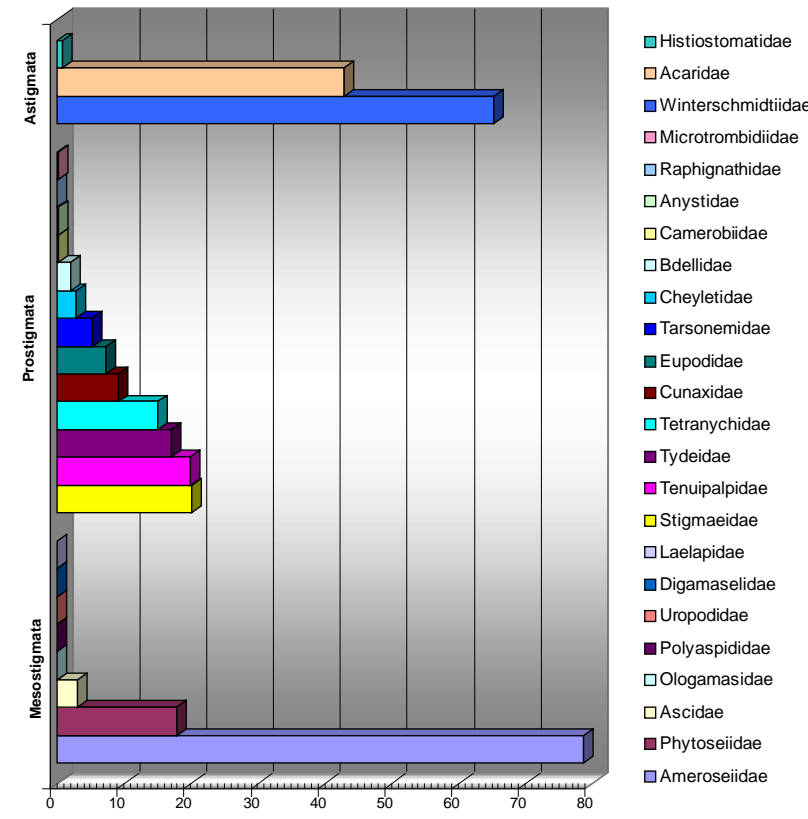

Figura 3 - Proporções das famílias de ácaros dentro de cada subordem, encontradas em Arecaceae em regiões da Mata Atlântica do Estado de São Paulo, 2000

Os 3 representantes da subordem Metastigmata encontrados neste trabalho pertenciam à família Ixodidae, e foram encontrados em frutos de A. aculeata. Entretanto, é possível que estes ácaros estivessem presentes no solo, uma vez que ao serem cortados, os frutos caíram ao solo, antes de serem coletados.

\section{2. Ácaros nos folíolos}

Não foram observadas diferenças significativas entre as espécies vegetais estudadas em relação à densidade de ácaros nos folíolos (Tabela 2). Entretanto, considerando-se as 6 famílias mais numerosas encontradas neste estudo, diferenças significativas (Duncan 5\%) foram verificadas para as famílias Phytoseiidae, Stigmaeidae, Tenuipalpidae e Tetranychidae (Tabela 2). Os fitoseídeos foram significativamente mais numerosos em $G$. brevispatha do que em E. edulis, A. dubia, A. aculeatissimum, $S$. romanzoffiana, A. aculeata e $S$. oleracea. Os stigmeídeos foram significativamente mais numerosos em G. schottiana do que nas demais espécies de palmeiras amostradas. Os tenuipalpídeos foram significativamente mais numerosos em $G$. brevispatha do que em G. schottiana, B. setosa, A. aculeatissimum, A. aculeata e $S$. oleracea. Os tetraniquídeos foram significativamente mais numerosos em $S$. oleracea do que em G. brevispatha, G. schottiana, B. setosa, A. dubia, A. aculeatissimum e A. aculeata. Estas diferenças nas quantidades de ácaros em algumas palmeiras coletadas pode ter ocorrido devido a uma influência da região de coleta (ambiente), uma vez que algumas espécies vegetais estudadas ocorriam em apenas um município, da planta coletada ou devido a uma interação das duas. 


\begin{tabular}{llcccccc}
\hline \multicolumn{1}{c}{ Espécie vegetal } & $\begin{array}{c}\text { Ácaros } \\
\text { (global) }\end{array}$ & \multicolumn{1}{c}{ Phy. } & Stig. & Ten. & Tetra. & Tyd. & Cun. \\
\hline G. brevispatha & $42,1 a$ & $23,4 a$ & $0,0 b$ & $9,6 a$ & $1,4 b c$ & $5,5 a$ & $1,4 \mathrm{a}$ \\
G.schottiana & $43,7 a$ & $13,7 a b$ & $20,6 a$ & $1,4 b$ & $0,0 c$ & $2,7 a$ & $2,7 a$ \\
B. setosa & $27,3 a$ & $13,2 a b$ & $2,5 b$ & $0,6 b$ & $0,6 c$ & $5,3 a$ & $2,5 a$ \\
E. edulis & $27,4 a$ & $10,5 b$ & $2,2 b$ & $4,2 a b$ & $4,4 a b$ & $1,9 a$ & $1,2 a$ \\
A. dubia & $25,6 a$ & $8,3 b$ & $2,5 b$ & $2,9 a b$ & $0,0 c$ & $3,4 a$ & $0,5 a$ \\
A. aculeatissimum & $12,8 a$ & $4,9 b$ & $3,1 b$ & $0,0 b$ & $0,5 c$ & $1,2 a$ & $1,2 a$ \\
S. romanzoffiana & $15,8 a$ & $4,3 b$ & $1,5 b$ & $3,5 a b$ & $1,8 a b c$ & $1,4 a$ & $0,5 a$ \\
A. aculeata & $11,7 a$ & $3,2 b$ & $4,4 b$ & $0,0 b$ & $0,2 c$ & $1,5 a$ & $0,5 a$ \\
S. oleracea & $10,5 a$ & $1,1 b$ & $0,7 b$ & $1,3 b$ & $4,9 a$ & $1,9 a$ & $0,0 a$ \\
\hline
\end{tabular}

Phy.= Phytoseiidae; Stig.= Sti gmaeidae; Ten.= Tenuipalpidae; Tetra.= Tetranychidae; Tyd.= Tydeidae; Cun.= Cunaxidae.

Em uma mesma coluna, médias seguidas pela mesma letra não diferem significativamente entre si pelo teste de Duncan (5\%).

Tabela 2. Número de ácaros por $10000 \mathrm{~cm}^{2}$ de folíolo, (considerando-se tanto a face ventral quanto a dorsal) para as famílias mais abundantes e para o total de todas as famílias encontradas.

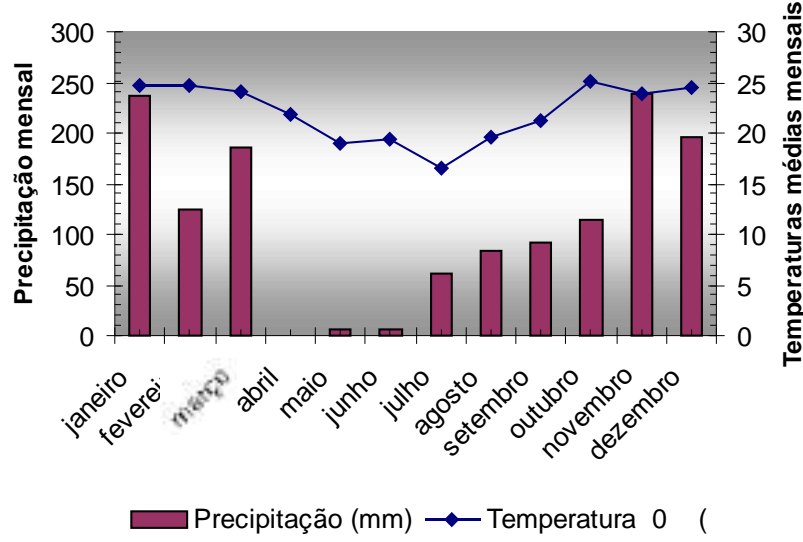

Figura 4 - Pluviosidade anual (mm: barras) e temperatura média do ar (c: linha pontilhada) de janeiro a dezembro de 2000 para região de Piracicaba.

Fonte: posto agrometeorológico da Escola Superior de Agricultura "Luiz de Queiroz" USP.

Um número significativamente maior de ácaros foi encontrado em folíolos na coleta realizada na estação seca (julho e agosto) que no início da estação chuvosa (outubro e novembro).

A redução na quantidade de ácaros durante as coletas da primavera provavelmente está relacionada com o aumento da precipitação observada nos meses em que foram realizadas (Figuras 4-5), visto que esta pode atuar diretamente nos ácaros, lavando-os das folhas. Yaninek et al. (1989) constataram uma redução substancial em populações de Mononychelus tanajoa (Bondar) sobre mandioca (Manihot esculenta Crantz) na África, por influência direta da precipitação. O número de ácaros dos

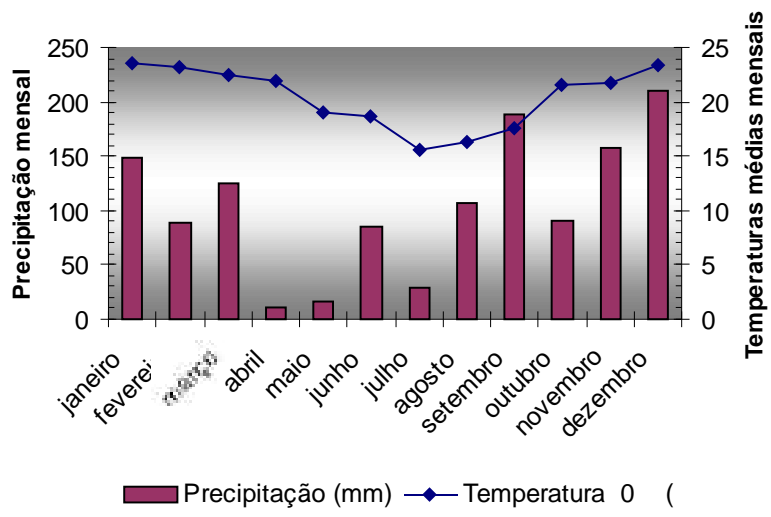

Figura 5 - Pluviosidade anual (mm: barras) e temperatura média do ar (c: linha pontilhada) de janeiro a dezembro de 2000 para região de Pariquera-Açu.

Fonte: Instituto Agronômico de Campinas

estágios ativos foi reduzido em até $82,4 \%$ em função da ação da chuva. Outra causa da redução do número de ácaros na primavera pode estar relacionada ao possível favorecimento da ação de patógenos de ácaros durante este período de maior precipitação, umidade relativa e temperatura (Alves \& Lecuona 1998). Alguns trabalhos têm sido publicados sobre patógenos que afetam ácaros em agroecossistemas no Brasil (Van der Geest et al. 2000). Entretanto, nada tem sido publicado sobre patógenos de ácaros na Mata Atlântica de São Paulo. Van der Geest et al. (2000) reviu o que se conhece sobre patógenos de ácaros em todo mundo, esclarecendo que os grupos aparentemente mais eficientes são vírus e fungos. 


\section{3. Ácaros nas inflorescências}

Foram encontrados 2.938 ácaros nas inflorescências avaliadas, das quais aproximadamente $98 \%$ pertenciam à família Ameroseiidae. Cerca de 99\% destes ácaros foram encontrados em inflorescências de $G$. schottiana e $G$. brevispatha (Tabela 3). Estes ácaros podem ser predadores, fungívoros ou alimentar-se de pólen. Podem ser encontrados no solo, em produtos armazenados, inflorescências e associados foreticamente a outros animais (Halliday 1997). O Ameroseidae Neocypholaelaps cocos Evans foi descrito de inflorescências de $C$. nucifera em Guadalcanal (Ilhas Solomon). Alguns Ameroseiidae dispersam-se por meio de associação forética com beijaflores (Halliday 1997).

Ascidae foi a segunda família mais abundante, mas corresponderam a apenas $1,3 \%$ do total de ácaros. Outras famílias encontradas, em proporções de no máximo $0,2 \%$ cada uma foram Phytoseiidae, Tarsonemidae, Stigmaeidae, Winterschmidtiidae e Acaridae.

Espécies de Ascidae também usam beijaflores para se dispersar, sendo transportados de uma inflorescência a outra nas cavidades nasais destas aves (Naskrecki \& Colwell 1998). Fain et al. (1977) estudaram uma espécie de Ascidae do gênero Rhinoseius Baker e Yunker coletada em narinas de beija-flor em Trinidad e em Belém do Pará, Brasil.

Outra possibilidade de dispersão dos ácaros de uma inflorescência a outra seria a associação forética com insetos da ordem Coleoptera, freqüentemente observados nas inflorescências coletadas. Fain et al. (1995), estudando ácaros associados a coleópteros da família Carabidae na Bélgica, encontrou alguns Ascidae do gênero Antennoseius além de representantes de outras famílias.

Walter \& Proctor (1999) relataram vários casos de associação de ácaros em inflorescências, incluindo Ascidae (Rhinoseius, Tropicoseius, Proctolelaps e Lasioseius), Ameroseiidae (Neocypholaelaps e Afrocypholaelaps) e Cryptostigmata (Scheloribatidae, Haplozetidae e Mochlozetidae).

Além destes, são citados em inflorescências alguns representantes da subordem Prostigmata como Eriophyoidea e Tarsonemidae (Krantz 1978).

Não foi possível obter inflorescências de A. dubia e A. aculeatissimum durante este estudo. Apesar das espécies de Geonoma apresentarem uma abundância muito maior de ácaros em relação às demais palmeiras analisadas, há que se considerar, entretanto, que as espécies vegetais coletadas apresentaram florescimento desigual ao longo do ano, e por esta razão a comparação estatística entre os números obtidos neste estudo não é adequada.

Aproximadamente $83 \%$ dos ácaros nas inflorescências foram coletados no início da estação seca. Quantidades relativamente elevadas de ácaros também foram coletados no início da estação chuvosa. Provavelmente esta maior quantidade de indivíduos está relacionada à maior produção de flores por planta nesta época do ano. Outra possível causa para esta maior abundância de ácaros nas coletas do início da estação seca é a diminuição da precipitação nesta época do ano, por motivos similares aos citados para os ácaros em folíolos.

As inflorescências de $S$. oleracea não apresentaram nenhum ácaro, entretanto estas continham sempre grande quantidade de insetos da ordem Thysanoptera. Três famílias desta ordem contêm espécies citadas como predadoras de tetraniquídeos (Chazeau 1985). Por outro lado, certos grupos de ácaros, principalmente Phytoseiidae, também têm sido citados como predadores de Thysanoptera (Eickwort 1983).

\begin{tabular}{|c|c|c|c|c|c|}
\hline \multirow[b]{2}{*}{ Espécie vegetal } & \multicolumn{4}{|c|}{ Meses de Coleta } & \multirow[b]{2}{*}{ Totais } \\
\hline & I - II & IV - V & VII- VIII & $\mathrm{X}-\mathrm{XI}$ & \\
\hline A. aculeata & - & - & - & 18 & 18 \\
\hline A. aculeatissimum & - & - & - & - & - \\
\hline A. dubia & - & - & - & - & - \\
\hline B. setosa & - & - & - & 22 & 22 \\
\hline E. edulis & 12 & - & - & 30 & 42 \\
\hline G. brevispatha & - & 1227 & 21 & 168 & 1416 \\
\hline G. schottiana & - & 1213 & 18 & 163 & 1394 \\
\hline S. oleracea & 0 & 0 & - & 0 & 0 \\
\hline S. romanzoffiana & 30 & - & - & 16 & 46 \\
\hline Totais & 42 & 2440 & 39 & 417 & \\
\hline
\end{tabular}

(-) Não foram coletadas inflorescências.

Tabela 3. Totais de ácaros encontrados em inflorescências de 9 espécies nativas de arecáceas da Mata Atlântica do Estado de São Paulo, nas quatro estações do ano. 


\section{4. Ácaros nos frutos.}

Foram encontrados 164 ácaros nos frutos das palmeiras estudadas, não se observando grandes diferenças entre o número de ácaros coletados em cada estação. As quantidades de ácaros foram sempre pequenas, obtendo-se no máximo um total de 14 indivíduos em frutos de $S$. romanzoffiana no verão (Tabela 4). Há que se considerar, entretanto, que os frutos das palmeiras estudadas variavam muito de tamanho além de que as espécies de palmeiras apresentaram frutificação desigual ao longo do ano. Estes fatores dificultam uma comparação estatística dos números obtidos.

Embora não muito abundantes, os ácaros coletados em frutos foram bastante diversos, representando 20 famílias diferentes. A família mais abundante foi Ascidae, correspondendo a $26 \%$ de todos os ácaros coletados. Outras famílias encontradas em proporções variando de 10-12\% dos ácaros coletados foram Phytoseiidae, Cheyletidae e Winterschmidtiidae.

As demais famílias encontradas em proporções sempre menores que $10 \%$ foram Tydeidae, Tenuipalpidae, Cunaxidae, Eupodidae, Acaridae, Ixodidae, Microtrombidiidae, Raphignathidae, Stigmaeidae, Tarsonemidae, Polyaspididae, Laelapidae e Camerobiidae.

Ácaros da superfamília Eriophyoidea têm sido citados em frutos de Arecaceae. Até recentemente, o ácaro A. guerreronis era conhecido em vários países das Américas e da África. Nesta, o primeiro relato do $A$. guerreronis foi feito em 1967, em Benin (Mariau 1977). Recentemente, o ácaro foi também encontrado na Ásia, onde o coqueiro tem importância maior que em outros continentes. Em Sri Lanka, A. guerreronis foi relatado pela primeira vez em 1997 (Fernando et al. 2000). Na Índia, este ácaro foi encontrado pela primeira vez em 1998 (Nair \& Koshy 2000). O ácaro vem causando sérios prejuízos à agricultura daqueles países (Haq 1999). A. guerreronis, causador da necrose e queda de frutos em coqueiro, foi o primeiro eriofídeo relatado em palmeiras no Brasil, no Estado do Rio de Janeiro (Robbs \& Peracchi 1965). Em seguida, este ácaro foi relatado no Estado de Pernambuco, causando a necrose do "olho do coqueiro" (Aquino \& Arruda 1967). Populações deste ácaro desenvolvem-se na região meristemática dos frutos, coberta pelas brácteas. A alimentação dos ácaros nesta região pode causar danos físicos de maneira que o tecido em formação danificado se expande, tornando-se evidente sobre o fruto uma superfície necrótica e suberificada, ocasionando frutos sem valor comercial devido a atrofia e deformação dos mesmos. (Mariau, 1986).

Outro ácaro encontrado em frutos de coqueiro, causando danos semelhantes ao A. guerreronis, é Steneotarsonemus furcatus DeLeon, da família Tarsonemidae (Ochoa et al. 1991). Além destes, têm sido relatados os ácaros Brevipalpus deleoni Prichard \& Baker, Dolichotetranychus vandergooti (Oudemans) e D. cocos Flechtmann \& Fernando, da família Tenuipalpidae (Flechtmann \& Fernando 2000).

\begin{tabular}{|c|c|c|c|c|c|}
\hline \multirow[b]{2}{*}{ Espécie vegetal } & \multicolumn{4}{|c|}{ Meses de Coleta } & \multirow[b]{2}{*}{ Totais } \\
\hline & I - II & IV - V & VII- VIII & $\mathrm{X}-\mathrm{XI}$ & \\
\hline A. aculeata & 0 & 4 & 3 & 2 & 9 \\
\hline A. aculeatissimum & - & 10 & 5 & 6 & 21 \\
\hline A. dubia & 2 & 2 & 3 & 6 & 13 \\
\hline B. setosa & - & 4 & 6 & 4 & 14 \\
\hline E. edulis & 4 & 12 & 6 & 12 & 34 \\
\hline G. brevispatha & - & 3 & 5 & 5 & 13 \\
\hline G. schottiana & 0 & 7 & 8 & 4 & 19 \\
\hline S. oleracea & 0 & 0 & 4 & 4 & 8 \\
\hline S. romanzoffiana & 14 & 10 & 4 & 4 & 32 \\
\hline Totais & 20 & 53 & 44 & 47 & \\
\hline
\end{tabular}

(-) não foram coletados frutos .

Tabela 4. Totais de ácaros encontrados em frutos de 9 espécies nativas de arecáceas da Mata Atlântica do Estado de São Paulo, nas quatro estações do ano. 


\begin{tabular}{|c|c|c|c|c|c|}
\hline \multirow[b]{2}{*}{ Espécie vegetal } & \multicolumn{4}{|c|}{ Meses de coleta } & \multirow[b]{2}{*}{ Totais } \\
\hline & I - II & IV - V & VII- VIII & $\mathrm{X}-\mathrm{XI}$ & \\
\hline A. aculeata & 11 & 2 & 0 & 2 & 15 \\
\hline A. aculeatissimum & 8 & 2 & 0 & 0 & 10 \\
\hline A. dubia & 0 & 0 & 0 & 0 & 0 \\
\hline B. setosa & 8 & 6 & 8 & 4 & 26 \\
\hline E. edulis & 8 & 6 & 6 & 0 & 20 \\
\hline G. brevispatha & 7 & 0 & 0 & 0 & 7 \\
\hline G. schottiana & 0 & 2 & 2 & 0 & 4 \\
\hline S. oleracea & 0 & 2 & 3 & 4 & 9 \\
\hline S. romanzoffiana & 2 & 10 & 7 & 4 & 23 \\
\hline Totais & 44 & 30 & 26 & 14 & \\
\hline
\end{tabular}

Tabela 5. Totais de ácaros encontrados em brotos terminais de 9 espécies nativas de arecáceas da Mata Atlântica do Estado de São Paulo, nas quatro estações do ano.

\section{5. Ácaros nos brotos terminais}

Foram coletados 114 ácaros nos brotos terminais das palmeiras examinadas (Tabela 5). Pelos mesmos motivos citados em relação às inflorescências e frutos, a comparação estatística entre os números obtidos em cada época de coleta para cada espécie de planta não é conveniente.

O eriofídio A. guerreronis foi encontrado por Flechtmann (1989) em bainhas foliares e brotos terminais da palmeira Lytocarium weddellianum (H. A. Wendland) proveniente de viveiro comercial.

Embora não muito abundantes, os ácaros coletados em brotos terminais apresentaram certa diversidade representando 15 famílias diferentes. A família mais abundante foi Tenuipalpidae, correspondendo a $21 \%$ de todos os ácaros coletados. Outras famílias encontradas em proporções variando de $10-13 \%$ dos ácaros coletados foram Ascidae, Phytoseiidae e Tarsonemidae. As demais famílias encontradas em proporções sempre menores que $10 \%$ foram Bdellidae, Acaridae, Cheyletidae, Cunaxidae, Tetranychidae, Tydeidae, Ologamasidae, Stigmaeidae, Uropodidae, Digamasellidae e Histiostomatidae.

\section{6. Gêneros dos ácaros encontrados}

Com relação a diversidade dos gêneros de ácaros encontrados em cada espécie vegetal estudada, pode-se observar que as plantas coletadas em maior número apresentaram uma maior quantidade de gêneros. E. edulis $\mathrm{e}$ $S$. romanzoffiana mostraram uma maior diversidade de gêneros de ácaros, 33 e 29 respectivamente. Estas palmeiras foram amostradas nas três regiões de coleta. $A$. aculeatissimum e B. setosa, oriundas das regiões de Cananéia e Pariquera-açu, apresentaram a mesma quantidade de gêneros de ácaros (24). A. dubia e $S$. oleracea também tiveram a mesma quantidade de gêneros de ácaros (16) apesar de coletadas em regiões distintas. $A$. aculeata, coletada apenas na região de Piracicaba, apresentou 15 gêneros de ácaros e G. brevispatha, amostrada na mesma região, apresentou 13. G. schottiana mostrou a menor diversidade de gêneros de ácaros, nove (Tabela 6). 


\begin{tabular}{|c|c|c|}
\hline Acrocomia aculeata & Laelapidae & Pseudoparasitus sp. \\
\hline & Phytoseiidae & Amblyseius sp. \\
\hline & & Euseius sp. \\
\hline & & Iphiseiodes sp. \\
\hline & & Phytoseius sp. \\
\hline & Ologamasidae & Cyrtolaelaps sp. \\
\hline & Cunaxidae & Scutopalus sp. \\
\hline & Cheyletidae & Hemicheyletia sp. \\
\hline & Stigmaeidae & Agistemus sp. \\
\hline & Tetranychidae & Oligonychus sp. \\
\hline & Tydeidae & Lorryia sp. \\
\hline & & Metatriophtydeus sp. \\
\hline & & Metapronematus sp. \\
\hline & & Parapronematus sp. \\
\hline & Winterschmidtiidae & Saproglyphus sp. \\
\hline Astrocarium aculeatissimum & Ascidae & Lasioseius sp. \\
\hline & & Melichares sp. \\
\hline & & Proctolaelaps sp. \\
\hline & Phytoseiidae & Amblyseius sp. \\
\hline & & Typhlodromips sp. \\
\hline & Polyaspididae & \\
\hline & Uropodidae & Phaulodinychus sp. \\
\hline & Anystidae & Erythracarus sp. \\
\hline & Bdellidae & Bdella sp. \\
\hline & Cunaxidae & Cunaxa sp. \\
\hline & & Rubroscirus sp. \\
\hline & & Pulaeus sp. \\
\hline & & Scutopalus sp. \\
\hline & Cheyletidae & Cheletomimus sp. \\
\hline & Stigmaeidae & Agistemus sp. \\
\hline & Tarsonemidae & Rhynchotarsonemus sp. \\
\hline & & Xenotarsonemus sp. \\
\hline & Tetranychidae & Tetranychus sp. \\
\hline & Tydeidae & Metatriophtydeus sp. \\
\hline & & Neolorryia sp. \\
\hline & & Pretydeus sp. \\
\hline & Acaridae & Neotropacarus sp. \\
\hline & & Tyrophagus sp. \\
\hline & Winterschmidtiidae & Saproglyphus sp. \\
\hline Attalea dubia & Ascidae & Asca sp. \\
\hline & & Proctolaelaps sp. \\
\hline & Phytoseiidae & Typhlodromips sp. \\
\hline & Cunaxidae & Rubroscirus sp. \\
\hline & Cheyletidae & Hemicheyletia sp. \\
\hline & & Mexecheles sp. \\
\hline & Eupodidae & Eupodes sp. \\
\hline & Stigmaeidae & Agistemus sp. \\
\hline & Tarsonemidae & Daidalotarsonemus sp. \\
\hline
\end{tabular}




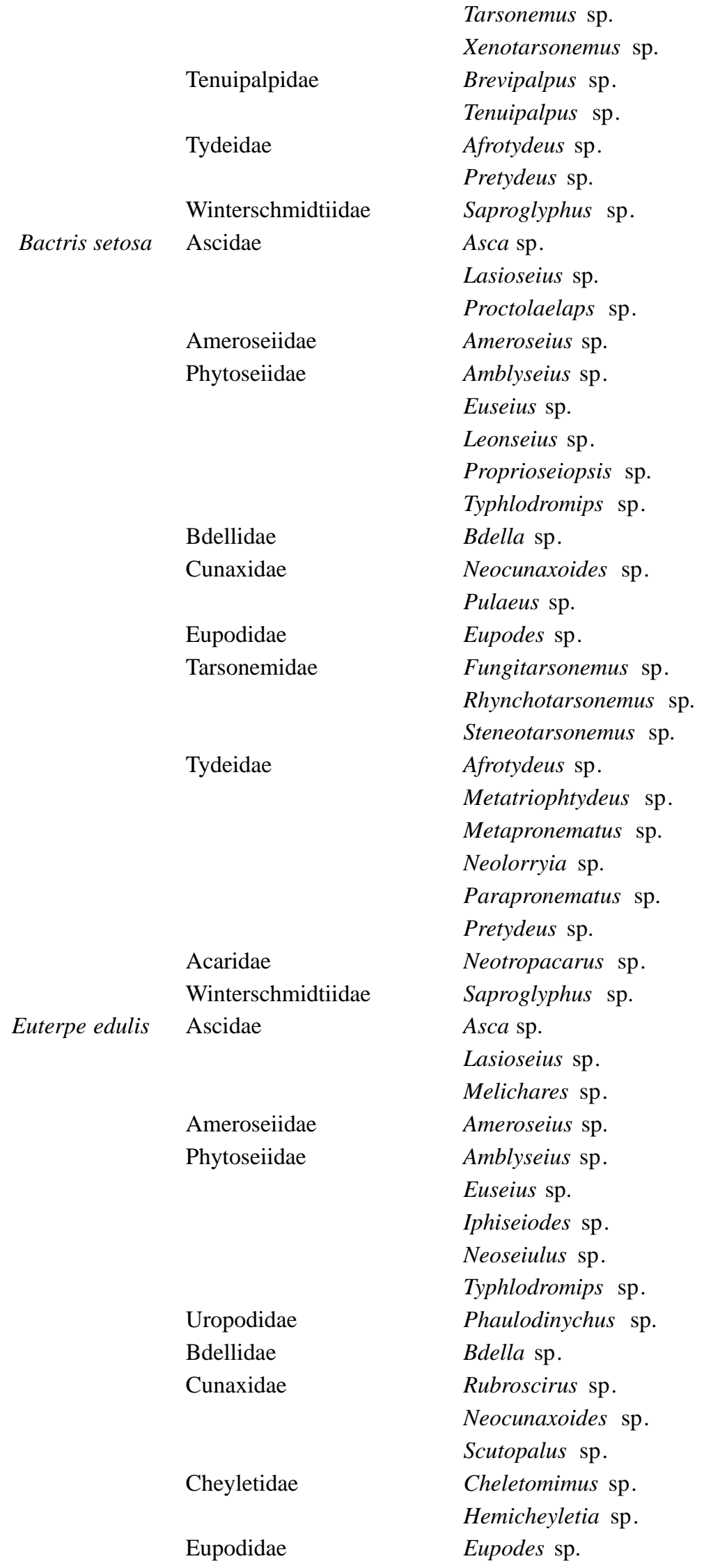


Stigmaeidae

Tarsonemidae

Tenuipalpidae

Tetranychidae

Tydeidae

Acaridae

Winterschmidtiidae

Geonoma brevispatha

Geonoma schottiana

Syagrus oleracea

$\begin{array}{ll}\text { Peonoma schottiana } & \text { Ascidae } \\ & \text { Cunaxidae } \\ & \text { Stigmaeidae } \\ & \text { Tenuipalpidae } \\ \text { Microtrombidiidae } & \text { Histiostomatidae } \\ \text { Syagrus oleracea } & \text { Ascidae } \\ & \text { Phytoseiidae } \\ & \text { Bdellidae } \\ \text { Cheyletidae } \\ \text { Tarsonemidae } \\ \\ \text { Tenuipalpidae }\end{array}$

Bdellidae

Cheyletidae

Camerobiidae

Tetranychidae

Tydeidae

Winterschmidtiidae
Agistemus sp.

Excelsotarsonemus sp.

Fungitarsonemus sp.

Brevipalpus sp.

Tenuipalpus sp.

Eutetranychus sp.

Oligonychus sp.

Schizotetranychus sp.

Tetranychus sp.

Afrotydeus sp.

Lorryia sp.

Metatriophtydeus sp.

Parapronematus sp.

Pretydeus sp.

Neotropacarus sp.

Saproglyphus sp.

Ameroseius sp.

Amblyseius sp.

Iphiseiodes sp.

Bdella sp.

Hemicheyletia sp.

Decaphyllobius sp.

Raphignathus sp.

Brevipalpus sp.

Tenuipalpus sp.

Eutetranychus sp.

Lorryia sp.

Pretydeus sp.

Saproglyphus sp.

Calvolia sp.

Asca sp.

Lasioseius sp.

Amblyseius sp.

Typhlodromips sp.

Armascirus sp.

Agistemus sp.

Brevipalpus sp.

Asca sp.

Lasioseius sp.

Amblyseius sp.

Iphiseiodes sp.

Bdella sp.

Prosocheyla sp.

Daidalotarsonemus sp.

Tarsonemus sp.

Brevipalpus sp. 


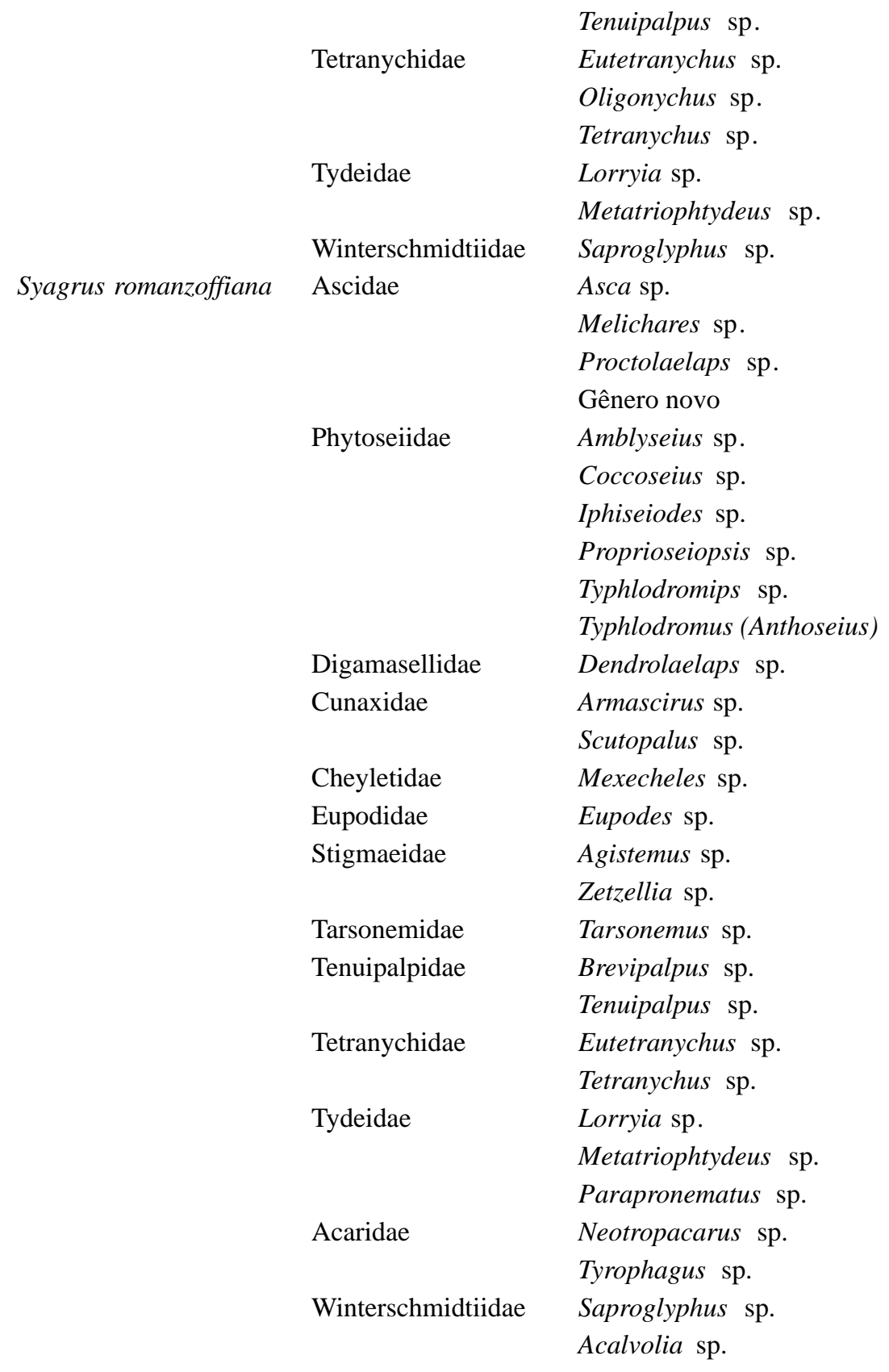




\section{SUBORDEM MESOSTIGMATA \\ SUPERFAMÍLIA ASCOIDEA \\ ASCIDAE Voigts \& Oudemans}

Asca spp.

Material Examinado: Cananéia: E. edulis folíolos (19-I) e frutos (18-IV); G. schottiana folíolos (11-X) e frutos (19-IV); Pariquera-Açu: B. setosa brotos terminais (18-IV); S. romanzoffiana brotos terminais (11VII) e folíolos (11-VII); A. dubia folíolos (12-X); E. edulis brotos terminais (11-VII); São Pedro: S. oleracea brotos terminais (11-XI).

\section{Lasioseius spp.}

Material Examinado: Cananéia: E. edulis inflorescências (11-X) e frutos (18-I); B. setosa frutos (19-IV e 12-VII); A. aculeatissimum frutos (19-IV); $G$. schottiana inflorescências (19-IV) e frutos (11-X); Pariquera-Açu: A. aculeatissimum frutos (11-VII e 10X); Piracicaba: E. edulis brotos terminais (07-II); São Pedro: S. oleracea frutos (11-XI).

\section{Melichares spp.}

Material Examinado: Pariquera-Açu: E. edulis inflorescências (18-I e $10-\mathrm{X}) ; S$. romanzoffiana inflorescências (18-I); A. aculeatissimum brotos terminais (17-I).

\section{Proctolaelaps $\mathrm{sp}$}

Material Examinado: Pariquera-Açu: A. dubia frutos (18-IV); S. romanzoffiana frutos (11-VII); B. setosa inflorescências (10-X); Cananéia: A. aculeatissimum frutos (19-IV); B. setosa frutos (11-X).

\section{Gênero não identificado}

Material Examinado: Pariquera-Açu: $S$. romanzoffiana inflorescências (17-I).

Observações: Ácaros da Família Ascidae foram bastante abundantes neste estudo. Dentre os gêneros encontrados, apenas Asca foi ocasionalmente verificado em folíolos.

\section{SUPERFAMÍLIA DERMANYSSOIDEA LAELAPIDAE Berlese}

\section{Pseudoparasitus sp.}

Material Examinado: Piracicaba: A. aculeata frutos $(17-\mathrm{V})$.

Ameroseius sp.

Material Examinado: Cananéia: G. schottiana inflorescências (19-IV, 12-VII e 11-X); E. Edulis inflorescências (11-X); B. setosa brotos terminais (19-IV); São Pedro: G. brevispatha inflorescências (16-V, 10-VIII e 16-XI).

Observações: Apesar da abundância com que foram encontrados, estes ácaros nunca foram verificados nos folíolos das palmeiras estudadas.

\section{PHYTOSEIIDAE Berlese}

\section{Amblyseius spp.}

Material Examinado: Cananéia: $S$. romanzoffiana folíolos (18-I e 11-X); E. edulis folíolos e frutos (18-I, 19IV, 12-VII e 11-X); B. setosa folíolos (19-IV, 12-VII e 11$\mathrm{X}) ;$ G. schottiana folíolos e frutos (12-VII); $A$. aculeatissimum folíolos (12-VII); Pariquera-Açu: $E$. edulis folíolos (18-I), frutos (19-I); S. romanzoffiana folíolos (18-I, 11-VII e 12-X), frutos (17-I e 11-VII); $A$. aculeatissimum folíolos (16-I, 11-VII e 12-X); B. setosa folíolos (18-IV, 11-VII e 12-X); Piracicaba: $S$. romanzoffiana brotos terminais e folíolos (17-V, 11-VIII); E. edulis folíolos (16-V e 11-XI); A. aculeata folíolos (11VIII); São Pedro: S. oleracea folíolos e frutos (16-V e 11$\mathrm{XI})$; G. brevispatha frutos (10-VIII).

Coccoseius sp.

Material Examinado: Cananéia: $S$. romanzoffiana folíolos (11-X).

\section{Euseius spp.}

Material Examinado: Pariquera-Açu: E. edulis folíolos (11-VII e 12-X); B. setosa folíolos (12-X); Piracicaba: E. edulis folíolos (07-II, 16-V e 10-XI); A. aculeata folíolos (17-V e 11-XI).

Iphiseiodes $\mathrm{sp}$.

Material Examinado: Piracicaba: A. aculeata folíolos (17-V e 11-VIII); E. edulis folíolos (16-V e 11$\mathrm{XI}), S$. romanzoffiana folíolos (16-V, 11-VIII e 11-XI); Pariquera-Açu: S. romanzoffiana folíolos (11-VII); São Pedro: G. brevispatha folíolos (11-VIII e 11-XI); $S$. oleracea folíolos (11-XI)

Leonseius sp.

Material Examinado: Cananéia: $B$. setosa folíolos (12-VII).

Neoseiulus sp.

Material Examinado: Cananéia: E. edulis brotos terminais e folíolos (12-VII).

Proprioseiopsis spp.

Material Examinado: Cananéia: $B$. setosa - folíolos (19-IV); Pariquera-Açu: B. setosa - folíolos (18-I e 11VII); S. romanzoffiana - frutos (10-X).

Phytoseius sp.

Material Examinado: Piracicaba: A. aculeata folíolos (17-V)

Typhlodromips spp.

Material Examinado: Cananéia: A. aculeatissimum folíolos (18-I); E. edulis folíolos (18-I, 12-VII e 11-X); B. 
setosa folíolos (18-I); G. schottiana folíolos (12-VII); S. romanzoffiana folíolos (11-X); Pariquera-Açu: E. edulis folíolos (16-I, 18-IV e 11-VII); A. aculeatissimum folíolos (16-I, 18-IV e 11-VII); A. dubia folíolos (16-I e 11-VII); $B$. setosa folíolos (16-I, 18-IV e 12-X); Piracicaba: E. edulis folíolos (11-VIII e 11-XI).

Typhlodromus (Anthoseius) sp.

Material Examinado: Cananéia: S. romanzoffiana folíolos (11-X); Piracicaba: S. romanzoffiana folíolos (7II).

Observações: As diferentes espécies desta família tão abundante foram encontradas em todas as partes das palmeiras examinadas.

\section{SUPERFAMÍLIA RHODACAROIDEA DIGAMASELLIDAE Evans}

Dendrolaelaps sp.

Material Examinado: Piracicaba: $S$. romanzoffiana brotos terminais $(16-\mathrm{V})$.

\section{OLOGAMASIDAE Ryke}

Cyrtolaelaps sp.

Material Examinado: Piracicaba: A. aculeata brotos terminais (07-II).

\section{SUPERFAMÍLIA POLYASPIDOIDEA POLYASPIDIDAE Berlese}

Material Examinado: Cananéia: A. aculeatissimum frutos (19-IV).

Observações:Foram coletados apenas dois indivíduos imaturos desta família, o que impossibilitou sua identificação.

\section{SUPERFAMÍLIA UROPODOIDEA UROPODIDAE Berlese}

Phaulodinychus sp.

Material Examinado: Pariquera-Açu: $A$. aculeatissimum frutos (18-IV); E. edulis brotos terminais (18-IV).

\section{SUPERFAMÍLIA BDELLOIDEA BDELLIDAE Dugès}

Bdella sp.

Material Examinado: Pariquera-Açu: E. edulis frutos (19-I); A. aculeatissimum folíolos (18-IV); $B$. setosa brotos terminais (10-X); São Pedro: S.oleracea brotos terminais (16-V); G. brevispatha frutos e brotos terminais (16-II).

Observações: Apenas em uma ocasião ácaros desta família foram encontrados em folíolos. Foram muito mais comuns em frutos e brotos terminais.

\section{CUNAXIDAE Thor}

Cunaxasp.

Material Examinado: Pariquera-Açu: $A$. aculeatissimum frutos (18-IV).

\section{Rubroscirus sp.}

Material Examinado: Pariquera-Açu: E. edulis folíolos (16-I); A. aculeatissimum folíolos (16-I, 18-IV e 11-VII); A. dubia folíolos (11-VII).

\section{Armascirus sp.}

Material Examinado: Cananéia: G. schottiana folíolos (12-VII); Piracicaba: S. romanzoffiana folíolos $(16-\mathrm{V})$

Neocunaxoides sp.

Material Examinado: Cananéia: E. edulis folíolos (18-I); B. setosa frutos (19-IV); Pariquera-Açu: E. edulis frutos (18-IV); B. setosa folíolos (11-VII).

\section{Pulaeus sp}

.Material Examinado: Cananéia: $B$. setosa folíolos (12-VII); Pariquera-Açu: B. setosa folíolos (16-I e 18IV).

Scutopalus sp.

Material Examinado: Pariquera-Açu: E. edulis folíolos (16-I); A. aculeatissimum folíolos (16-I); $S$. romanzoffiana folíolos (11-VII); Piracicaba: A. aculeata brotos terminais (17-V).

Observações: Ainda que encontrados em certas ocasiões em frutos e em brotos terminais, os ácaros desta família foram mais comuns nos folíolos das palmeiras estudadas.

\section{SUPERFAMÍLIA CHEYLETOIDEA CHEYLETIDAE Leach}

\section{ANYSTIDAE Oudemans}

Erythracarus sp.

Material Examinado: Pariquera-Açu: $A$. aculeatissimum frutos (18-IV e 10-X).
Cheletomimus sp.

Material Examinado: Pariquera-Açu: $A$. aculeatissimum brotos terminais (17-I); A. dubia folíolos (11-VII); Piracicaba: E. edulis frutos (30-V). 
Hemicheyletia sp.

Material Examinado: Pariquera-Açu: A. dubia frutos (18-IV); E. edulis frutos (30-V e 11-VII); Piracicaba: A. aculeata - frutos (11-VIII); São Pedro: $G$. brevispatha frutos e brotos terminais (16-V).

\section{Mexecheles spp.}

Material Examinado: Pariquera-Açu: $S$. romanzoffiana frutos (17-I e 18-IV); A. dubia frutos (11$\mathrm{X})$.

Prosocheylasp.

Material Examinado: São Pedro: $S$. oleracea folíolos (11-XI).

Observações: Em apenas 2 ocasiões estes ácaros foram encontrados em folíolos e brotos terminais. Foram muito mais comuns em frutos.

\section{SUPERFAMÍLIA EUPODOIDEA EUPODIDAE Koch}

Eupodes sp.

Material Examinado: Cananéia: $S$. romanzoffiana folíolos (12-VII), B. setosa frutos (12-VII); G. schottiana frutos (12-VII); Pariquera-Açu: $S$. romanzoffiana folíolos (16-I, 18-IV e 11-VII); E.edulis folíolos (16-I, 18IV, 11-VII e 12-XI); B. setosa folíolos (16-I); A. dubia folíolos (11-VII).

\section{SUPERFAMÍLIA RAPHIGNATHOIDEA CAMEROBIIDAE Southcott}

Decaphyllobius sp.

Material Examinado: São Pedro: $G$. brevispatha folíolos (16-V) e frutos (16-XI).

\section{RAPHIGNATHIDAE Kramer}

Raphignathus sp.

Material Examinado: São Pedro: G. brevispatha frutos $(16-\mathrm{V})$.

\section{STIGMAEIDAE Oudemans}

Agistemus spp.

Material Examinado: Cananéia: A. aculeatissimum brotos terminais (IV-00) e folíolos (VII-00 e X-00); $G$. schottiana folíolos (I-00, IV-00 e VII-00); E. edulis folíolos (I-00) e frutos (I-00); S. romanzoffiana folíolos (IV-00, VII-00 e X-00); Pariquera-Açu: $A$. aculeatissimum folíolos (I-00 e IV-00); S. romanzoffiana folíolos (IV-00 e VII-00); E. edulis folíolos (IV-00 e VII00); A. dubia folíolos (VII-00); Piracicaba: A. aculeata inflorescências (XI-00), brotos terminais (II-00) e folíolos (II-00, V-00 e XI-00); E. edulis folíolos (II-00 e XI-00); $S$. romanzoffiana folíolos (VIII-00 e XI-00).
Zetzelliasp.

Material Examinado: Pariquera-Açu: $S$. romanzoffiana folíolos (IV-00).

Observações: Esta foi a segunda família mais numerosa nos folíolos das palmeiras estudadas, sendo esporadicamente encontrada em inflorescências, frutos e brotos terminais.

\section{SUPERFAMÍLIA TARSONEMOIDEA TARSONEMIDAE Kramer}

Daidalotarsonemus sp.

Material Examinado: Pariquera-Açu: A. dubia folíolos (11-VII); São Pedro: S. oleracea folíolos (16-V).

Excelsotarsonemus sp

.Material Examinado: Pariquera-Açu: E. edulis folíolos (16-I).

Fungitarsonemus sp.

Material Examinado: Cananéia: E. edulis folíolos (18-I); Pariquera-Açu: B. setosa folíolos (12-X); Piracicaba: E. edulis folíolos (7-II).

\section{Rhynchotarsonemus sp.}

Material Examinado: Cananéia: A. aculeatissimum brotos terminais (18-I); B. setosa brotos terminais (19-IV e 12-VII).

Steneotarsonemus sp.

Material Examinado: Cananéia: $B$. setosa brotos terminais (19-IV) e frutos (12-VII); Pariquera-Açu: $B$. setosa brotos terminais (18-IV).

Tarsonemus sp.

Material Examinado: Pariquera-Açu: A. dubia folíolos (11-VII); Piracicaba: $S$. romanzoffiana folíolos (07-II); São Pedro: S. oleracea folíolos (16-V).

Xenotarsonemus sp.

Material Examinado: Cananéia: $A$. aculeatissimum folíolos (12-VII); Pariquera-Açu: A. dubia folíolos (11VII).

\section{SUPERFAMÍLIA TETRANYCHOIDEA TENUIPALPIDAE Berlese}

Brevipalpus sp.

Material Examinado: Cananéia: E. edulis folíolos (18-I) e frutos (19-IV); G. schottiana inflorescências (19IV) e frutos (12-VII); Pariquera-Açu: E. edulis folíolos (11-VII e 12-X); A. dubia folíolos (12-X); Piracicaba: E. edulis folíolos (07-II, 16-V e 11-VIII); S. romanzoffiana folíolos (11-VIII); São Pedro: S. oleracea folíolos (16-V e 10-VIII); G. brevispatha folíolos (10-VIII), brotos terminais (16-II) e frutos (16-XI).

\section{Tenuipalpus sp.}


Material Examinado: Cananéia: S. romanzoffiana folíolos (18-I, 19-IV e 12-VII) e brotos terminais (12-VII); E. edulis folíolos e brotos terminais (19-IV e 19-IV); Pariquera-Açu: E. edulis folíolos e brotos terminais (17I, 18-IV, 11-VII e 11-VII); S. romanzoffiana folíolos e brotos terminais (18-IV); A. dubia folíolos (11-VII e 12X); Piracicaba: S. romanzoffiana folíolos (07-II, 17-V e $16-\mathrm{V})$ e brotos terminais (11-VIII e 11-XI); E. edulis brotos terminais (07-II); São Pedro: G. brevispatha brotos terminais (16-II); S. oleracea folíolos (16-V) e brotos terminais (10-VIII).

Observações: Ácaros desta família tão numerosa foram encontrados em todas as partes das plantas.

\section{TETRANYCHIDAE Donnadieu}

\section{Eutetranychus spp.}

Material Examinado: Pariquera-Açu: E. edulis folíolos (16-I); S. romanzoffiana folíolos (11-VII); Piracicaba: S. romanzoffiana folíolos (07-II, 16-V e 11XI); São Pedro: S. oleracea folíolos (16-V-2000); G. brevispatha folíolos (10-VIII).

\section{Oligonychus sp.}

Material Examinado: Pariquera-Açu: E. edulis folíolos (18-IV); Piracicaba: E. edulis folíolos (16-V e 11-VIII); A. aculeata brotos terminais (17-V) e frutos (11XI); São Pedro: S. oleracea folíolos (16-V e 10-VIII) e brotos terminais (11-XI)

Schizotetranychus sp.

Material Examinado: Cananéia: E. edulis folíolos (18-I e 12-VII); Pariquera-Açu: E. edulis folíolos (18IV).

Tetranychus sp.

Material Examinado: Cananéia: A. aculeatissimum folíolos (18-I e 19-IV); B. setosa folíolos (18-I e 19-IV); S. romanzoffiana folíolos (12-VII); Pariquera-Açu: $E$. edulis folíolos (16-I e 18-IV); S. romanzoffiana folíolos (18-IV e 12-X); Piracicaba: S. romanzoffiana folíolos (07-II, 16-V e 11-XI); São Pedro: S. oleracea folíolos (16V) e brotos terminais (11-XI).

Observações: Com exceção das raras vezes em que foram observados em brotos terminais, estes ácaros foram encontrados quase exclusivamente nos folíolos.

\section{SUPERFAMÍLIA TROMBIDIOIDEA MICROTROMBIDIIDAE Thor}

Material Examinado: Cananéia: G. schottiana frutos (19-IV).

Observações: apenas um indivíduo foi encontrado sem condições adequadas para identificação ao nível de gênero.

\section{SUPERFAMÍLIA TYDEODEA TYDEIDAE Kramer}

Afrotydeus sp.

Material Examinado: Cananéia: $B$. setosa folíolos (12-VII); Pariquera-Açu: A. dubia folíolos (16-I e 11-VII); E. edulis folíolos (16-I e 11-VII); $B$. setosa folíolos (11-VII).

\section{Lorryia spp.}

Material Examinado: Pariquera-Açu: E. edulis folíolos (18-IV); S. romanzoffiana folíolos (11-VII); Piracicaba: E. edulis brotos terminais (07II e 30-V) e frutos (10-XI); A. aculeata folíolos (17V) e frutos (11-XI); São Pedro: S. oleracea folíolos (16-V) e frutos (10-VIII); G. brevispatha frutos (10VIII).

Metatriophtydeus spp.

Material Examinado: Cananéia: $S$. romanzoffiana folíolos (18-I, 19-IV, 12-VII e 11-X); A. aculeatissimum folíolos (12-VII); B. setosa folíolos (12-VII); Pariquera-Açu: $A$. aculeatissimum folíolos (16-I); S. romanzoffiana folíolos (16-I e 12-X); Piracicaba: A. aculeata folíolos (07-II); E. edulis folíolos (11-XI); São Pedro: S. oleracea folíolos (16-V).

\section{Metapronematus sp.}

Material Examinado: Pariquera-Açu: $B$. setosa folíolos (18-IV); Piracicaba: A. aculeata folíolos (07-II).

\section{Neolorryia sp.}

Material Examinado: Cananéia: $A$. aculeatissimum - folíolos (12-VII); B. setosa folíolos (12-VII).

\section{Parapronematus sp.}

Material Examinado: Cananéia: $B$. setosa folíolos (12-VII); Pariquera-Açu: $S$. romanzoffiana folíolos (11-VII); Piracicaba: A. aculeata folíolos (07-II); S. romanzoffiana folíolos (11-XI); E. edulis brotos terminais (07-II).

Pretydeus sp.

Material Examinado: Pariquera-Aç: $B$. setosa folíolos (16-I); E. edulis folíolos (16-I); A. aculeatissimum folíolos (16-I); A. dubia folíolos (12-X); Cananéia: A. aculeatissimum folíolos (19IV); São Pedro: G. brevispatha folíolos (11-XI). 


\section{SUBORDEM ASTIGMATA SUPERFAMÍLIA ACAROIDEA ACARIDAE Ewing \& Nesbitt}

\section{Neotropacarus sp.}

Material Examinado: Cananéia: A aculeatissimum folíolos (18-I); B. setosa folíolos (18-I); E. edulis folíolos (19-IV); Pariquera-Açu: S. romanzoffiana folíolos (11VII); A. aculeatissimum folíolos (12-X); B. setosa folíolos (12-X); Piracicaba: E. edulis folíolos (16-V, 11VIII); S. romanzoffiana folíolos (11-VIII).

\section{Tyrophagus sp.}

Material Examinado: Cananéia: S. romanzoffiana brotos terminais (11-X); Pariquera-Açu: $S$. romanzoffiana frutos (18-IV); A. aculeatissimum frutos (11-VII).

\section{WINTERSCHMIDTIIDAE Oudemans}

\section{Saproglyphus sp.}

Material Examinado: Cananéia: A. aculeatissimum folíolos (18-I, 12-VII); B. setosa brotos terminais (18-I); S. romanzoffiana inflorescências e frutos (18-I e 11-X); Pariquera-Açu: E. edulis folíolos (16-I), frutos (19-I); S. romanzoffiana frutos (18-IV e 11-VII); $A$. aculeatissimum folíolos (16-I); A. dubia folíolos (16-I, 11-VII); Piracicaba: E. edulis folíolos (07-II); A. aculeata folíolos (07-II e 11-XI); S. romanzoffiana frutos (30-V); São Pedro: G. brevispatha inflorescências (10VIII); S. oleracea frutos (10-VIII).

Acalvolia sp.

Material Examinado: Cananéia: S. romanzoffiana folíolos (19-IV).

Calvolia sp.

Material Examinado: São Pedro: G. brevispatha frutos $(16-\mathrm{XI})$

\section{SUPERFAMÍLIA HISTIOSTOMATOIDEA HISTIOSTOMATIDAE Berlese}

Material Examinado: Cananéia: G. schottiana brotos terminais (19-IV).

Observações: Foi coletado apenas 1 indivíduo imaturo desta família o que impossibilitou sua identificação.

\section{AGRADECIMENTOS}

Ao Dr. Warren Calvin Welbourn do Florida Department of Agriculture and Consumer Services, pela identificação do ácaro Microtrombidiidae e confirmação dos gêneros de Cunaxidae, Eupodidae e Anystidae. Ao engenheiro agrônomo Venésio Felipe dos Santos, estatístico da Empresa Pernambucana de Pesquisas Agropecuária (IPA), pelo auxílio nas análises estatísticas; ao biólogo Lázaro Vanderlei F. Silva, técnico de laboratório do Setor de Zoologia Agrícola da ESALQ-USP, pelo auxílio na coleta e montagem dos ácaros; ao Instituto Agronômico de Campinas pelo suporte técnico e logístico; ao $\mathrm{CNPq}$ (Conselho Nacional de Desenvolvimento Científico e Tecnológico); ao PRONEX (Programa de Apoio a Núcleos de Excelência, Ministério da Cultura e Tecnologia) pelo suporte financeiro, este trabalho foi apoiado pela Fundação de Amparo à Pesquisa do Estado de São Paulo (FAPESP) no âmbito do Programa BIOTA/FAPESP O Instituto Virtual da Biodiversidade (www.biota.org.br).

\section{REFERÊNCIAS BIBLIOGRÁFICAS}

ALVES, S. B. \& LECUONA, R.E. 1998. Epizootiologia aplicada ao controle microbiano de insetos. In: ALVES, S. B. (Ed.). Controle microbiano de insetos. Piracicaba: FEALQ. cap. 5, p.97-169.

AMRINE, J. W.; MANSON, D. C. M. 1996. Preparation, Mounting and Descriptive Study of Eriophyoid Mites. In: LINDQUIST, E. E.; SABELIS, M. W.; BRUIN, J. (Ed.). Eriophyid mites: their biology, natural enemies and control. Amsterdan: Elsevier, p.383-396.

AQUINO, M. L. N.; ARRUDA, G. P. 1967. O agente causal da "necrose do olho do coqueiro" em Pernambuco. Recife: Instituto de Pesquisas Agronômicas, 33p. (Boletim técnico, 27).

CHAZEAU, J. 1985. Predaceous insects. In: HELLE, W.; SABELIS, N. W: (Ed.) World crop pests: spider mites, their biology, natural enemies and control. Amsterdam: Elsevier, v. 1B, p.211-246.

EICKWORT, G. C. 1983. Potencial use of mites as biological control agents of leaf-feeding insects. In: HOY, M. A.; CUNNINGHAM, G. L.; KNUTSON, L. Biological control of pests by mites. Berkeley: University of California, cap.6, p.41-52.

FAIN, A.; HYLAND, K. E.; AITKEN, T. H. G. 1977. Flower mites of the family Ascidae phoretic in nasal cavities of birds (Acarina: Mesostigmata). Acta Zool. Pathol. Antw. v. 69, p.99-154.

FAIN, A.; NOTI, M. I.; DUFRÊNE, M. 1995. Observations on the mites (Acari) associated with carabidae (Coleoptera) in Belgium. I. Annotated list of the species. Internat. J. Acarol. v. 21, n. 2, p.107-122.

FERNANDO, L. C. P.; WICKRAMANANDA, J. R. \& ARATCHIGE, N. S. 2000. Status of coconut mite, Aceria guerreronis in Sri Lanka. In: International Workshop on Coconut Mite (Aceria guerreronis). 6-8 January 2000, Coconut Research Institute, Lunuwila, Sri Lanka. p.6.

FERREIRA, L. G. S. 1997. Pupunha (Bactris gasipaes H. B. K.). In: COORDENADORIA DE ASSISTÊNCIA TÉCNICA INTEGRAL. Manual técnico das culturas. Campinas, p.317-331.

FLECHTMANN, C. H. W. 1967. Phytoseiidae do Estado de São Paulo (Acarina: Mesostigmata). Anais da Escola Superior de Agricultura "Luiz de Queiroz", v.24, p.247-248. 
FLECHTMANN, C. H. W. 1975. Elementos de acarologia. São Paulo: Livraria Nobel, 1975.344 p.

FLECHTMANN, C. H. W. 1989. Cocos weddelliana Wendl. (Palmae: Arecaceae), a new host plant for Eriophyes guerreronis (Keifer, 1965) (Acari: Eriophyidae) in Brazil. Internat. J. Acarol. v. 15, p.241.

FLECHTMANN, C. H. W. 1994. Amrineus cocofolius n.g., n.sp. (Acari: Eriophyidae) from Brazil. Internat. J. Acarol.v. 20, p.57-59.

FLECHTMANN, C. H. W. 1998. Mite (Arthropoda: Acari) associates of palms (Arecaceae) in Brazil. IV. Description of two new species in the family Eriophyidae. Internat. J. Acarol. v.24, n.2, p.113-117.

FLECHTMANN, C. H. W. \& SANTANA, D. L. Q. 1997. Ocorrência de Notostrix attenuata Keifer (Acari: Eriophyidae) em coqueiros no Brasil. In: CONGRESSO BRASILEIRO DE ENTOMOLOGIA, 16., Salvador, 1997. Resumos. Salvador: S. E. B. 1997. p.40.

FLECHTMANN, C. H.; FERNANDO, C. P. 2000. Dolichotetranychus cocos n.sp. from the perianth of coconuts in Sri Lanka (Acari: Tenuipalpidae). Internat. J. Acarol. v. 26, n. 2, p.145-153.

GONSALVES, A. D. 1955. O babaçu, considerações científicas, técnicas e econômicas. Rio de Janeiro: Ministério da Agricultura, 331p. (Série Estudos e Ensaios, 8).

GONDIM Jr., M.G.C. 2000. Ácaros de palmeiras (Arecaceae) em áreas dos Estados de São Paulo e Pernambuco. 161 p. Tese de doutorado, Universidade de São Paulo, Piracicaba.

GONDIM Jr., M. G. C.; FLECHTMANN, C. H. W. MORAES, G. J. de. 2000. Mite (Arthopoda: Acari) associates of palm (Arecaceae) in Brazil. IV. Descriptions of four new species in the Eriophyoidea. Syst. Appl. Acarol. v. 5, p.99-110.

GONDIM Jr., M. G. C.; MORAES, G. J. de. 2001. Phytoseiidae mites (Acari: Phytoseiidae) associated with palm trees (Arecaceae) in Brazil. Syst. Appl. Acarol. v. 6, p.65-94.

HALLIDAY, R. B. 1997. Revision of the Australian Ameroseiidae (Acarina: Mesostigmata). Invertebrate Taxonomy, v. 10, p.179-201.

HAQ, M. A. 1999. Distribution of the coconut mite Aceria guerreronis in Peninsular India and adjacent islands. Entomon, v. 24, n. 4, p.371-379.

JARDIM, M. A. G.; ANDERSON, A. B. 1987. Manejo de populações nativas de açaizeiro no estuário amazônico. Boletim de Pesquisa Florestal, v. 15, p.18.

JOLY, A. B. 1991. Botânica: introdução à taxonomia vegetal. São Paulo: Editora Nacional, 777p.

KRANTZ, G.W. 1978. A manual of acarology. Corvalis: Oregon State University Bookstores, 509p.

LORENZI, H. 1993. Árvores brasileiras manual de identificação e cultivo de plantas arbóreas nativas do Brasil. Nova Odessa: Editora Plantarum, 384p.

LORENZI, H. 1996. Palmeiras do Brasil: nativas e exóticas. Nova Odessa: Editora Plantarum, 303p.
MARIAU, D. 1977. Aceria (Eriophyes) guerreronis: an important pest of African and American coconut grooves. Oléagineux, v. 32, n. 3, p.109-111.

MARIAU, D. 1986. Comportament d Eriophyes guerreronis Keifer à legard de différents variétés de cocotiers. Oléagineux, v. 41, p.499-505.

MOORE, D.; HOWARD, F. W. 1996. Coconuts. In: LINDQUIST, E. E.; SABELIS, M. W.; BRUIN, J. (Ed.). Eriophyid mites: their biology, natural enemies and control. Amsterdan: Elsevier, p.561-570.

NAIR, C. P. R.; KOSHY, P. K. Studies on coconut eriophyid mite, Aceria guerreronis Keifer in India. In: International workshop on coconut mite (Aceria guerreronis). 6-8 January 2000, Coconut Research Institute, Lunuwila, p.7.

NASKRECKI, P.; COLWELL, R. K. 1998. Monographs: systematics and host plant affiliations of hummingbird flower mites of the genera Tropicoseius Baker \& Yunker and Rhinoseius Baker \& Yunker (Acari: Mesostigmata: Ascidae). Maryland: Ent. Soc. Amer 185p.

OCHOA, R.; AGUILAR, H.; VARGAS, C. 1991. Ácaros fitófagos da America Central: guia ilustrada. Turrialba: CATIE, 251p.

ROBBS, C. F.; PERACCHI, A. L. 1965. Sobre a ocorrência de um ácaro prejudicial ao coqueiro (Cocos nucifera L.) In: REUNIÃO FITOSSANITÁRIA, Rio de Janeiro, 1965. Anais. Rio de Janeiro, p.65-70.

SANTANA, D. L. Q.; FLECHTMANN, C. H. W. 1998. Mite (Arthropoda: Acari) associates of palms (Arecaceae) in Brazil. I. Present status and new records. Rev. Brasil. Zool. v. 15, n.4, p.959-963,

SANTANA, D. L. Q.; FLECHTMANN, C. H. W.; LIMA, M. F. 1994. Novos ácaros do coqueiro no Brasil. Aracaju: EMBRAPA, CNPCO, $4 \mathrm{p}$.

VAN DER GEEST, L. P. S.; ELLIOT, S. L.; BREEUWER, J. A. J. 2000. Diseases of mites. Exp. Appl. Acarol. v. 24, p.497-560.

WALTER, D. E.; PROCTOR, H. C. 1999. Mites: ecology, evolution and behaviour. New York: CABI publishing, 320p.

YANINEK, J. S.; HERREN, H. R.; GUTIERREZ, A. P. 1989. Dynamics of Mononychellus tanajoa (Acari: Tetranychidae) in Africa: seasonal factors affecting phenology and abundance. Environ. Entomol. v. 18, n. 4, p.625-631.

Título: Grupos de ácaros (arthropoda, acari) encontrados em arecaceae da mata atlântica do estado de são paulo. Autores: Geraldo Pereira de Arruda Filho \& Gilberto José de Moraes

Biota Neotropica, Volume 2, número 1, 2002 -

http://www.biotaneotropica.org.br/v2n1/pt/abstract?inve ntory+BN01102012002

Recebido em 01 de março de 2002 - Revisado em 20 de junho de 2002 - Publicado em 30 de junho de 2002

ISSN 1676-0603 